\title{
Temperature Measurements in Neonates: Assessing the Agreement of Two Methods
}

\author{
Yetunde Olasinde', Moninuola Ernest ${ }^{2}$, Gbenga Popoola ${ }^{3}$, Omotayo Adesiyun $^{4}$, Kolade Ernest ${ }^{*}$ \\ ${ }^{1}$ Department of Paediatrics, Bowen University Teaching Hospital, Ogbomoso, Nigeria \\ ${ }^{2}$ Department of Dental Surgery, University of Ilorin Teaching Hospital, Ilorin, Nigeria \\ ${ }^{3}$ Resaerch Clinician, WHO Randomized Clinical Trial of Poliomyelitis Vaccines, Ilorin, Nigeria \\ ${ }^{4}$ Department of Paediatrics, University of Ilorin Teaching Hospital, Ilorin, Nigeria \\ Email: *kolade.ernest@gmail.com
}

How to cite this paper: Olasinde, Y., Ernest, M., Popoola, G., Adesiyun, O. and Ernest, K. (2020) Temperature Measurements in Neonates: Assessing the Agreement of Two Methods. Open Journal of Pediatrics, 10, 224-230.

https://doi.org/10.4236/ojped.2020.101022

Received: February 27, 2020

Accepted: March 23, 2020

Published: March 26, 2020

Copyright $\odot 2020$ by author(s) and Scientific Research Publishing Inc. This work is licensed under the Creative Commons Attribution International License (CC BY 4.0).

http://creativecommons.org/licenses/by/4.0/

(c) (i) Open Access

\begin{abstract}
Background: Neonatal temperature response during illness is unpredictable. Whereas accurate temperature measurement is an important diagnostic step in Neonatal practice. Abnormalties in temperature pattern may be a pointer to a sinister condition especially in neonates, whose thermoregulatory mechanism is immature. There are several methods of temperature measurements and the search for a suitable thermometry method in neonates continues. This study compared the forehead non touch infra-red thermometer (NTIT) with the axilllary mercury-in-glass (MIGT) method of temperature measurement in neonates. Method: Four hundred babies aged 1 to 28 days were recruited from the immunization clinic of the University of Ilorin Teaching Hospital between August 2016 and May 2017. Temperatures were taken using both NTIT and MIGT in the standard way and recorded. Result: The mean age and SD was $5.10 \pm 4.28$ days. Pearson correlation showed a positive correlation between the Axillary Mercury-in-Glass and Forehead Non-Touch Infra-red thermometry readings $(\mathrm{r}=0.426, p<0.001)$. Bland-Altman method revealed a good agreement between both methods of thermometry as $95.5 \%$ of the readings were within the limits of agreement. Conclusion: Axillary Mercury-in-Glass thermometer and Forehead Non touch Infra-red thermometers have a good agreement and can be used interchangeably in neonates.
\end{abstract}

\section{Keywords}

Neonates, Axillary Mercury-in-Glass Thermometer, Forehead Non-Touch Infra-Red Thermometer, Bland-Altman

\section{Introduction}

Accurate temperature measurement is an important diagnostic step in paediatric 
practice especially in the newborn whose thermoregulatory mechanism is immature [1] [2]. Abnormalities in temperature pattern such as a fever or hypothermia may point to problematic conditions such as infections in the newborn [3]. Different sites exist for measurement of core body temperature, but the most reliable is the pulmonary artery [3] [4]. Other sites are the distal oesophagus, nasopharynx, rectum, tympanic membrane and the bladder [3] [4]. Measurement of the temperature at these sites is however invasive and best avoided. Temperature reading depends on the site used, however, the commonest sites in children are the axilla, mouth and rectum.

Several instruments exist for temperature estimation but the quest for a suitable thermometer for temperature measurement in the newborn still continues [5]. Suitability measures include safety, speed, accuracy and cost-effectiveness of the thermometer [5]. Methods of thermometry commonly used in children include; mercury-in-glass (MGIT), electronic (Digital) and Non Touch infra-red thermometers (NTIT) [3]. While mercury-in-glass thermometers are inexpensive and widely available in developing countries, they contain mercury and so are not recommended due to the potential toxicity of mercury if the thermometer is broken [3]. Electronic thermometers are relatively more expensive, but provide an accurate and faster way to measure body temperature [3]. Infra-red thermometers are newer and more promising devices in terms of speed and the non-contact nature confers on it, the advantage for infection control, especially in the newborn whose immune system is not fully developed [6].

Several studies [1] [2] [7] [8] [9] have proposed differing results on the appropriate temperature measurement methods in children. Jarvis et al. [7] although recorded a poor agreement between digital axillary and infra-red thermometers, reported that the infra-red thermometer showed only minimal changes on the neonatal behavioural scale when both thermometers were used in preterm newborns. This connotes that the use of infra-red thermometer caused less disturbance or pain to the newborn during temperature measurement. Similarly, Robertson-Smith et al. [8] and Sethi et al. [2] reported a poor agreement between mid-forehead and digital axillary thermometry readings amongst newborns in an intensive care unit thus concluding that both methods of thermometry could not be used interchangeably in the newborn. Sollai et al. [1] and De Curtis et al. [9] on the other hand, reported a good agreement between Infra-red and axillary digital thermometry; and Infra-red and rectal mercury-in-glass thermometry respectively, in newborns. This study aimed to compare the traditional axillary mercury-in-glass thermometric readings with forehead Non Touch Infra-red thermometric readings in neonates.

\section{Method}

The study was a cross-sectional descriptive study and was carried out between August 2016 and May 2017 at the Immunization Clinic of the University of Ilorin Teaching Hospital, Ilorin. Ethical clearance was obtained as part of a larger 
study from the University of Ilorin Teaching Hospital Ethics and Research Committee. The minimum sample size required for the study estimated using the Cochran's formula (at a prevalence of 50) was 384. Allowing for a $10 \%$ non-response rate, 422 neonates were recruited into the study, however 22 neonates had incomplete data and 400 neonates were eventually analysed (giving a response rate of 95\%). Subject recruitment was carried out by the Researcher and two research assistants who had been duly trained by the Researcher. After a clear explaination had been given to the mother/caregiver, and verbal consent sought from her, a study proforma was administered in an interview form to obtain relevant socio-demographic features such as age of the baby, social class and immunisation history. A brief physical examination was also carried out on the babies. The elligible babies and their mothers were made to sit in the same room with a constant room temperature. Temperature of babies was taken thus:

Using the NTIT: The NTIT was held at a maximum distance of $5 \mathrm{~cm}$ from the midpoint of the forehead area until the signal tone was heard (average of $1-2$ secs). Temperatures were taken 3 times and the average reading calculated and recorded.

Using the MIGT: The MIGT was cleaned with alcohol swab and shaken before each use, to drop the mercury column to below $35^{\circ} \mathrm{C}$ and placed in the axilla for 3 - 5 minutes before the reading was taken. One reading was taken for each patient. The MIGT was then cleaned again with an alcohol swab.

\subsection{Selection Criteria}

\section{Inclusion Criteria}

1) Well babies aged 1 - 28 days attending the immunisation clinic whose mothers granted consent to participate in the study.

\section{Exclusion criteria}

1) Babies whose parents did not give consent.

2) Babies who were ill.

\subsection{Data Analysis}

Data were entered into a computer and analysed with SPSS version 21.

Pearson correlation was used to determine the relationship between the two methods of temperature measurements, while Bland-Altman method was used to test for level of agreement between them. Level of agreement was said to be good as if $95 \%$ of the data laid between $1.96 \mathrm{SD}$ of the mean difference between the two methods [10]. According to previous studies, mean of difference was considered good if $<0.5^{\circ} \mathrm{C}$, and satisfactory if $<0.6^{\circ} \mathrm{C}$ [1] [2].

\section{Results}

A total of 400 babies were recruited into the study; of these, 207 (51.8\%) were males and 193 (48.2\%) were females, with a M:F ratio of 1:1. The mean \pm SD age was $5.10 \pm 4.28$ days. The Mean \pm SD birth-weight was $3.13 \pm 0.63 \mathrm{~kg}$. Other de- 
tails are as shown in Table 1.

There was no significant difference between temperatures taken with the NTIT and the MGIT as shown in Table 2.

Using the Pearson correlation technique, there was a positive relationship between the two methods of temperature measurements. $(\mathrm{r}=0.426, p<0.001)$ Further details are as shown in Figure 1.

The Bland-Altman plot showed a good agreement between the two methods as $95.5 \%(382 / 400)$ of the paired differences in the readings fell within the limit of agreement. Number of outliers was $8 / 400(4.5 \%)$ The mean difference between the two thermometers was 0.02 .

The width of agreement was narrow (2.0108) with a lower limit of -0.9878 (95\% CI, -1.0763 to -0.8993 ) and an upper limit of 1.0230 (95\% CI, 0.9345 to 1.1115). Other details are as shown in Figure 2.

\section{Discussion}

The mean body temperature of newborns obtained with the axillary MGIT in the current study was similar to that reported in healthy newborns studied by Sollai et al. [1], but much lower than that reported by Chiappini [12]; probably due to the fact that Chiappini studied febrile children. Also, the mean temperatures

Table 1. Socio-demographic variables of the study participants.

\begin{tabular}{|c|c|c|}
\hline Variable & Frequency $(N=400)$ & Percent \\
\hline \multicolumn{3}{|l|}{ Age (days) } \\
\hline Mean \pm SD & \multicolumn{2}{|c|}{$5.10 \pm 4.28$} \\
\hline Range & \multicolumn{2}{|c|}{$1.0-28.0$} \\
\hline \multicolumn{3}{|l|}{ Sex } \\
\hline Male & 207 & 51.8 \\
\hline Female & 193 & 48.2 \\
\hline \multicolumn{3}{|l|}{ Birth weight (Kg) } \\
\hline Mean \pm SD & \multicolumn{2}{|c|}{$3.13 \pm 0.63$} \\
\hline Range & \multicolumn{2}{|c|}{$1.00-4.70$} \\
\hline \multicolumn{3}{|l|}{ Place of birth } \\
\hline Home & 60 & 15.0 \\
\hline Traditional birth & 28 & 7.0 \\
\hline Mission & 38 & 9.5 \\
\hline Hospital & 254 & 63.5 \\
\hline Others & 20 & 5.0 \\
\hline \multicolumn{3}{|l|}{ Social class } \\
\hline High & 228 & 57.0 \\
\hline Middle & 150 & 37.5 \\
\hline Low & 22 & 5.5 \\
\hline
\end{tabular}

Kg: Kilogram, Oyedeji classification of Social Class [11]: classes I\&II: High social class, social class III: middle class, Social classes IV\&V: Low social class. 
Table 2. Mean body temperature.

\begin{tabular}{cccc}
\hline Variable & Mean \pm SD & T & $p$ value \\
\hline NTIT Temperature reading & $36.80 \pm 0.50$ & 0.668 & 0.505 \\
Axillary (MGIT) reading & $36.78 \pm 0.45$ & & \\
\hline
\end{tabular}

t: Paired samples $\mathrm{T}$ test.

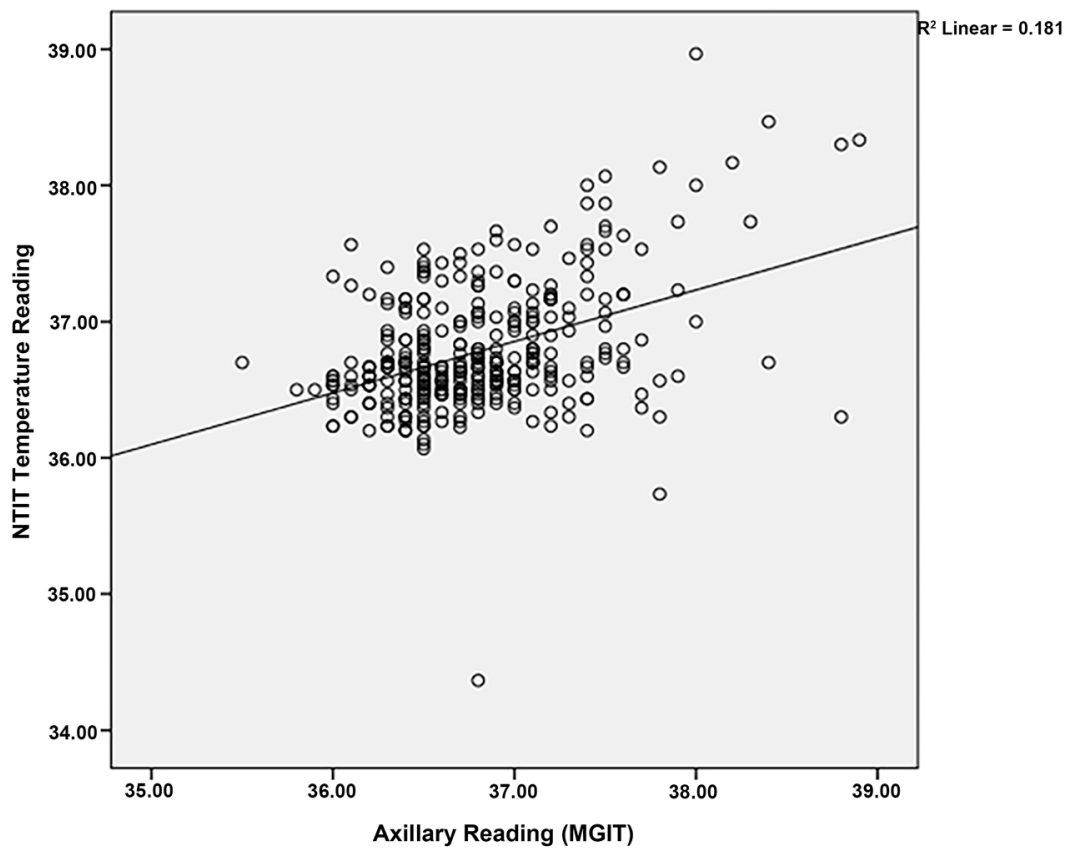

Figure 1. Correlation of temperature reading between Non-touch infrared thermometer (NTIT) and Axillary Mercury in Glass Thermometer (MGIT).

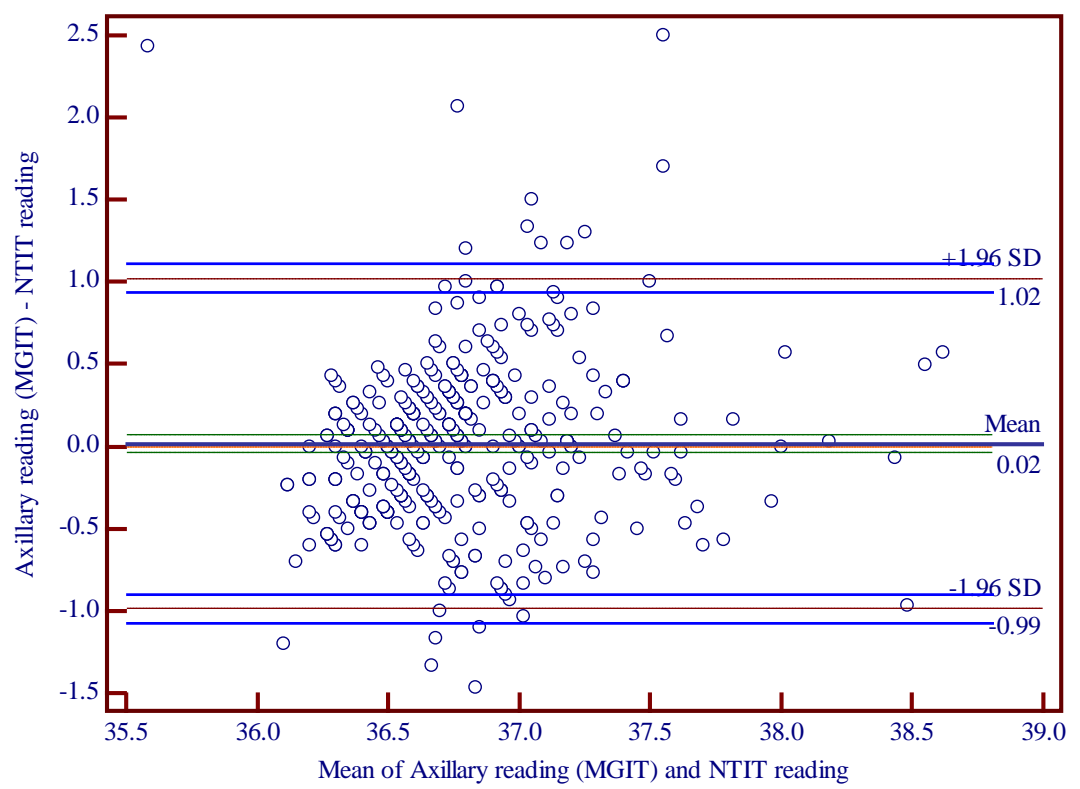

Figure 2. Bland Altman Graph showing the limit of agreement between the MIGT and NTIT readings. 
obtained by the two methods of thermometry were similar, simulating the report of Chiappini et al. [12] who stated no significant difference between the mean thermometric readings obtained by both axillary MGIT and forehead NTIT methods.

The significant positive correlation between the two thermometry methods showed that both thermometers can be used interchangeably. This is similar to previous studies by Gasim [13] and Edelu [14], though carried out amongst older children.

The mean difference in the current study was similar to a previous study by Sollai et al. [1]. Furthermore, the number of outliers was small; connoting that there was no great difference in the paired readings taken with both devices. In the same light, the two thermometers showed a good agreement, as the limit of agreement was narrow. This is similar to the reports of Sollai [1], Chiappini [12] and De Curtis [9] who also reported a good agreement between NTIT and mercury thermometers. This is however contrary to the findings of Sethi [2], Jarvis [7] and Robertson-Smith [8] who reported poor agreement between digital axillary and forehead infra-red thermometers. The reason for the disparity may be due to the fact these authors compared temperature readings using axillary digital thermometers and NTIT as opposed to axillary Mercury-in-glass thermometers used in this study; further stressing the fact that temperature measurement differed with the device used in measuring it [3].

\section{Conclusion}

Axillary MGIT and forehead NTIT had a good positive correlation and a good level of agreement.

\section{Recommendation}

For speed, convenience, safety and infection control, axillary MGIT can be replaced by forehead NTIT in neonates.

\section{Limitation of the Study}

Rectal temperature, which is a better estimate of the core temperature in neonates was not carried out in this study and may be a line of future research in this age group.

\section{Funding}

No specific Grants available for this work.

\section{Conflicts of Interest}

The authors declare no conflicts of interest regarding the publication of this paper.

\section{References}

[1] Sollai, S., et al. (2016) Performance of a Non-Contact Infrared Thermometer in 
Healthy Newborns. Paediatrics Research, 6, e008695 https://doi.org/10.1136/bmjopen-2015-008695

[2] Sethi, A., Patel, D., Nimbalkar, A., Phatak, A. and Nimbalkar, S. (2013) Comparison of Forehead Infrared Thermometry with Axillary Digital Thermometry in Neonates. Indian Pediatrics, 50, 1153-1154. https://doi.org/10.1007/s13312-013-0302-y

[3] Leduc, D. and Woods, S. (2000) Temperature Measurement in Paediatrics. Paediatrics \& Child Health (Oxford), 5, 273-276. https://doi.org/10.1093/pch/5.5.273

[4] Thye, S.L., Sabirin, J. and Bakri, R. (2012) Infrared Thermometer.

[5] El-Radhi, A.S. (2014) Determining Fever in Children: The Search for an Ideal Thermometer. The British Journal of Nursing, 23, 91-94. https://doi.org/10.12968/bjon.2014.23.2.91

[6] National Institute for Health Research (2015) Non-Contact Infrared Thermometers. Diagnostic Evidence Co-Operative.

[7] Jarvis, M., Guy, K.J. and König, K. (2013) Accuracy of Infrared Thermometers in Very Low Birth Weight Infants and Impact on Newborn Behavioural States. Journal of Paediatrics and Child Health, 49, 471-474. https://doi.org/10.1111/jpc.12207

[8] Robertson-Smith, J., McCaffrey, F.T., Sayers, R., Williams, S. and Taylor, B.J. (2015) A Comparison of Mid-Forehead and Axillary Temperatures in Newborn Intensive Care. Journal of Perinatology, 35, 120-122. https://doi.org/10.1038/jp.2014.148

[9] DeCurtis, M., Calzolari, F., Marciano, A., Cardilli, V. and Barba, G. (2008) Comparison between Rectal and Infrared Skin Temperature in the Newborn. ADC Fetal \& Neonatal Edition, 93, F55-57.

[10] Bland, J. and Altman, D. (1999) Measuring Agreement in Method Comparison Studies. SAGE Journals, 8, 135-160. https://doi.org/10.1191/096228099673819272

[11] Oyedeji, G. (1985) Socio-Economic and Cultural Background of Hospitalized Children in Ilesha, Nigeria. Nigerian Journal of Paediatrics, 12, 111-118.

[12] Chiappini, E., et al. (2011) Performance of Non-Contact Infrared Thermometer for Detecting Febrile Children in Hospital and Ambulatory Settings. Journal of Clinical Nursing, 20, 1311-1318. https://doi.org/10.1111/j.1365-2702.2010.03565.x

[13] Gasim, G.I., Musa, I.R., Abdien, M.T. and Adam, I. (2013) Accuracy of Tympanic Temperature Measurement Using an Infrared Tympanic Membrane Thermometer. BMC Research Notes, 6, 194. https://doi.org/10.1186/1756-0500-6-194

[14] Edelu, B.O., Ojinnaka, N.C. and Ikefuna, A.N. (2011) Fever Detection in under 5 Children in a Tertiary Health Facility Using the Infrared Tympanic Thermometer in the Oral Mode. Italian Journal of Pediatrics, 37, 8. https://doi.org/10.1186/1824-7288-37-8 